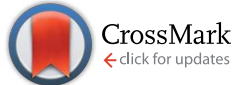

Cite this: RSC Adv., 2015, 5, 66360
Received 11th July 2015

Accepted 30th July 2015

DOI: $10.1039 / \mathrm{c} 5 \mathrm{ra13580j}$

www.rsc.org/advances

\section{The marine-derived fungus Tinctoporellus sp. CBMAI 1061 degrades the dye Remazol Brilliant Blue $R$ producing anthraquinones and unique tremulane sesquiterpenes $\uparrow$}

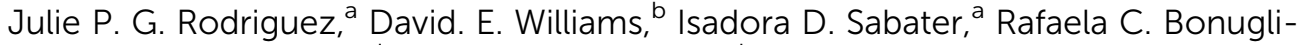
Santos, ${ }^{c}$ Lara D. Sette, ${ }^{\text {cd }}$ Raymond J. Andersen ${ }^{\mathrm{b}}$ and Roberto G. S. Berlinck ${ }^{* a}$

Degradation of the dye Remazol Brilliant Blue R (RBBR) by the marine-derived fungus Tinctoporellus sp. CBMAI 1061 led to the formation of four unprecedented anthraquinones, of which two were halogenated. Investigation of the RBBR degradation medium also led to the isolation of three new tremulene terpenes, of which two bear novel 2-hydroxy- or 2-methoxy-3,4-dihydro-2H-pyrrole $\mathrm{N}$-oxide moieties. The products of RBBR degradation and of the fungus metabolism have been identified by analysis of spectroscopic data.

\section{Introduction}

Synthetic dyes are key components in various industrial processes of high economic value. Recently the world's market for both pigments and dyes was forecast to reach U\$ 26.53 billion by the year 2017. ${ }^{1}$ However, synthetic dyes are recalcitrant chemicals that have proven difficult to degrade and are potentially environmentally harmful when disposed of in large quantities. ${ }^{2}$ Remazol Brilliant Blue R (RBBR, 1) is a synthetic dye widely used in textile pigmentation, because of its stability, intense blue color and strong attachment to textiles through covalent bonding. ${ }^{2}$ RBBR (1) is also considered as a potentially toxic chemical. ${ }^{3}$ Currently there is much interest in developing environmentally friendly procedures for RBBR degradation, such as photocatalysis ${ }^{4}$ and bioremediation.

An array of fungal strains have been investigated as potential RBBR bioremediation agents. ${ }^{3-6}$ The marine-derived fungus

${ }^{a}$ Instituto de Química de São Carlos, Universidade de São Paulo, CP 780, CEP 13560-970, São Carlos, SP, Brazil. E-mail: rgsberlinck@iqsc.usp.br; Fax: +55-1633739952; Tel: $+55-16-33739954$

${ }^{b}$ Departments of Chemistry and Earth, Ocean \& Atmospheric Sciences, University of British Columbia, Vancouver, BC, V6T 1Z1, Canada. E-mail: raymond.andersen@ ubc.ca; Fax: +1604822 6088; Tel: +16048224511

'Divisão de Recursos Microbianos, Centro Pluridisciplinar de Pesquisas Quimicas, Biológicas e Agrícolas, Universidade Estadual de Campinas, Rua Alexandre Cazelatto, 999, Paulinia, SP, Brazil. E-mail: rafaellabonugli@gmail.com; Fax: +5519-21392852; Tel: +55-19-21392895

${ }^{d}$ Departamento de Bioquimica e Microbiologia, Instituto de Biociências, Universidade Estadual Paulista "Júlio de Mesquita Filho", Campus Rio Claro, Av. 24-A, 1515, Rio Claro, SP, Brazil. E-mail: larasette@rc.unesp.br; Fax: +55-19-35264176; Tel: +5519-35264171

$\dagger$ Electronic supplementary information (ESI) available: ${ }^{1} \mathrm{H},{ }^{13} \mathrm{C}$ NMR and HRMS spectra for compounds 2-5, and ${ }^{1} \mathrm{H}$ and ${ }^{13} \mathrm{C}$ NMR spectra for compounds 6-8. See DOI: $10.1039 / \mathrm{c} 5 \mathrm{ra} 13580 \mathrm{j}$
Tinctoporellus sp. CBMAI 1061 was found to degrade RBBR (1) efficiently, promoting a 90\% decolorization of RBBR-containing growth medium in 12 days. ${ }^{7}$ However, the products of degradation remained unknown. Considering the importance of RBBR dye to the textile industry, a knowledge of the RBBR degradation products would help in the selection of a bioremediation procedure. With this in mind we set out to investigate the products of RBBR transformation by Tinctoporellus $\mathrm{sp}$. CBMAI 1061. Herein, we report on the kinetics of the degradation process and the isolation and identification of the anthraquinone RBBR degradation products 2 to 5 . Investigation of the culture medium obtained from the RBBR biotransformation by Tinctoporellus sp. CBMAI 1061 has also resulted in the isolation of the three new tremulene terpenes 6 to 8 , two of which bear structurally unprecedented 2-hydroxy- or 2-methoxy3,4-dihydro- $2 \mathrm{H}$-pyrrole $\mathrm{N}$-oxide moieties.
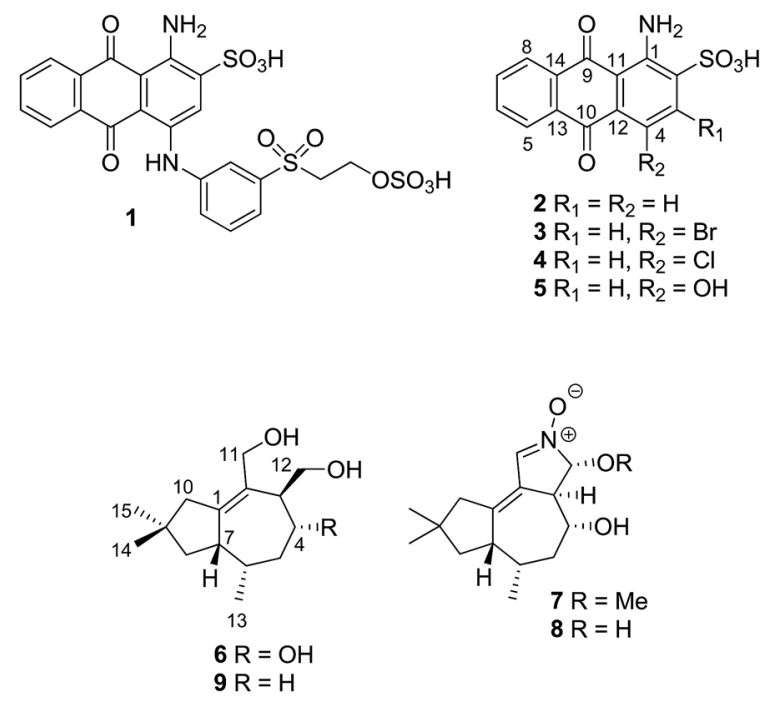

$6 \mathrm{R}=\mathrm{OH}$ 


\section{Results and discussion}

Incubation of Tinctoporellus sp. CBMAI 1061 in $200 \mathrm{~mL}$ of growth medium containing $10 \mathrm{mg}$ of RBBR (1) promoted the dye degradation in 12 days. Between day 13 and 17 no significant change of the growth medium UV absorption could be verified. The fungus Tinctoporellus sp. CBMAI 1061 was subsequently grown at a $6 \mathrm{~L}$ scale under the same conditions for 12 days. After filtration, the liquid medium was adsorbed on a $1: 1: 1$ mixture of XAD-2, -4 and -7 resins. Washing the resin mixture with $1: 1$ $\mathrm{MeOH} /$ acetone, followed by evaporation of the organic solvent mixture, yielded $1.2 \mathrm{~g}$ of a crude extract that was fractionated by gel filtration on Sephadex $\mathrm{LH} 20(\mathrm{MeOH})$, followed by $\mathrm{C}_{18}$ reversed-phase flash column chromatography. Subsequent reversed-phase HPLC purification of each of the resulting fractions in turn gave the anthraquinones 2-5 along with tremulenes 6-8.

The HRFTESIMS analysis of 2 gave a $[\mathrm{M}-\mathrm{H}]^{-}$ion at $m / z$ at 322.0117 appropriate for a molecular formula of $\mathrm{C}_{14} \mathrm{H}_{9} \mathrm{NO}_{5} \mathrm{~S}$. The ${ }^{13} \mathrm{C}$ NMR spectrum showed twelve aromatic carbon resonances between $\delta 150$ and 110, along with two carbonyl resonances at $\delta 184.09$ and 182.74. Considering that 2 was isolated as a RBBR (1) degradation product, the fourteen signals observed in ${ }^{13} \mathrm{C}$ NMR spectrum of 2 suggested the presence of an anthraquinone, and, therefore, the presence of a sulfonic acid group could be deduced from the molecular formula. Analysis of the $1 \mathrm{D}^{1} \mathrm{H}$ and COSY NMR spectra of 2 identified a 1,2-disubstituted benzene ring, with signals of four hydrogen atoms at $\delta 8.14(\mathrm{dd}, J=8.0,2.0 \mathrm{~Hz}), 7.85(\mathrm{dd}, J=8.0,2.0 \mathrm{~Hz})$, $7.91(\mathrm{dd}, J=8.0,2.0 \mathrm{~Hz}$ ), and $8.23(\mathrm{dd}, J=8.0,2.0 \mathrm{~Hz})$, as well as a pair of ortho aromatic hydrogens $(\delta 7.94(\mathrm{~d}, J=8.0 \mathrm{~Hz})$ and $7.41(\mathrm{~d}, J=8.0 \mathrm{~Hz})$ ) that suggested the presence of a 1,2,3,4tetrasubstituted benzene ring. Two exchangeable hydrogen resonances, that were found to not correlate to carbons in the HSQC spectrum, were observed at $\delta 9.32$ and 7.49. These structural features along with the molecular formula suggested that the structure of compound 2 could be assigned as 1-amino9,10-dioxo-9,10-dihydroanthracene-2-sulfonic acid. Analysis of the HMBC spectrum confirmed this proposal. Key HMBC correlations were observed between C-10 ( $\delta$ 182.74) and both $\mathrm{H}-4(\delta$ 7.41) and $\mathrm{H}-5(\delta$ 8.14), between $\mathrm{H}-8(\delta$ 8.23) and $\mathrm{C}-9(\delta$ 184.09), between $\mathrm{H}-3$ ( $\delta$ 7.94) and C-1 ( $\delta$ 148.56), and between $\mathrm{H}-4$ and $\mathrm{C}-2$ ( $\delta$ 138.16). Compound 2, as well as being an unreported RBBR (1) degradation product, is a new anthraquinone. The cleavage of the amino group at C-4 in RBBR (1), presumably by an enzymatic reaction promoted by the fungus Tinctoporellus sp. CBMAI 1061, leading to an unsubstituted anthraquinone at C-4 has not been previously reported.

Comparison of the spectroscopic data obtained for degradation products 3-5 with the data recorded for degradation product 2 allowed us to routinely assign their structures. The HRFTMS of 3 gave $[\mathrm{M}-\mathrm{H}]^{-}$ions at $\mathrm{m} / \mathrm{z} 379.9230$ and 381.9206 in a $1: 1$ ratio, indicating the presence of a bromine atom in 3 , and corresponding to the molecular formula $\mathrm{C}_{14} \mathrm{H}_{8} \mathrm{NO}_{5} \mathrm{SBr}$. The molecular formula differs from that of 2 by the loss of a hydrogen and the addition of a bromine atom. In the ${ }^{1} \mathrm{H}$ NMR spectrum, the doublets assigned to $\mathrm{H}-3$ and $\mathrm{H}-4$ in 2 are no longer seen and instead a sharp singlet at $\delta 8.03$ is observed that correlates to a $\mathrm{sp}^{2}$ carbon at $\delta 138.79$ in the HSQC spectrum. A bromine substitutent at C-3 or C-4 would account for these ${ }^{1} \mathrm{H}$ NMR differences and the molecular formula. Most likely the $\mathrm{Br}$ substituent is at C-4, since in the $\mathrm{HMBC}$ spectrum the $\mathrm{H}-3$ resonance at $\delta 8.03$ strongly correlates to carbons at $\delta 148.23$, 106.06 and 131.27 that were assigned to C-1, C-4 and C-12, respectively. Hence, the structure of 3 was assigned as that of 1-amino-4-bromo-9,10-dioxo-9,10-dihydroanthracene-2-sulfonic acid.

The HRFTMS of compound 4 showed $[\mathbf{M}-\mathbf{H}]^{-}$ions at $\mathrm{m} / \mathrm{z}$ 335.9733 and 337.9728 in a $3: 1$ ratio, appropriate for the molecular formula $\mathrm{C}_{14} \mathrm{H}_{8} \mathrm{NO}_{5} \mathrm{SCl}$, containing a chlorine atom instead of the bromine atom seen in 3 . The ${ }^{1} \mathrm{H}$ NMR spectrum of 4 was very similar to that of 3 , except the singlet at $\delta 8.03$ in 3 had been replaced by a singlet at $\delta 7.82$. In all other respects 3 and 4 appeared to be identical suggesting that the structure of 4 was 1amino-4-chloro-9,10-dioxo-9,10-dihydroanthracene-2-sulfonic acid. The small amount of $\mathbf{4}$ obtained precluded the acquisition of $1 \mathrm{D}{ }^{13} \mathrm{C}$ and $2 \mathrm{D}-\mathrm{NMR}$ data.

The HRFTESIMS spectrum of 5 gave a $[\mathrm{M}-\mathrm{H}]^{-}$ion at $\mathrm{m} / \mathrm{z}$ 318.0073 , appropriate for the molecular formula $\mathrm{C}_{14} \mathrm{H}_{9} \mathrm{NO}_{6} \mathrm{~S}$, that differs from that of 2 by the addition of an oxygen atom. In the ${ }^{1} \mathrm{H}$ NMR spectrum the doublets assigned to $\mathrm{H}-3$ and $\mathrm{H}-4$ in $\mathbf{2}$, as in $\mathbf{3}$ and $\mathbf{4}$, are no longer seen and instead a singlet at $\delta 7.56$ is observed. The limited quantity of $\mathbf{5}$, as with $\mathbf{4}$, precluded the recording of $1 \mathrm{D}{ }^{13} \mathrm{C}$ and $2 \mathrm{D}-\mathrm{NMR}$ data. However, by analogy with 3 and 4, a hydroxyl substitutent at C-4 would account for the $1 \mathrm{D}{ }^{1} \mathrm{H}$ NMR data and the molecular formula. Therefore, the structure of 5 is tentatively assigned as 1-amino-4-hydroxy-9,10dioxo-9,10-dihydroanthracene-2-sulfonic acid.

Investigations on the RBBR biological degradation have been performed using either immobilized enzymes, mainly laccases, or crude fungal growth media and the degradation products have been analyzed by UV, HPLC-MS or HPLC-UV-MS. ${ }^{8-18}$ Degradation of RBBR (1) by the fungus Polyporus sp. S133 resulted in the formation of a hydroxylated product, which, although mistakenly named, was suggested to be sodium 1amino-4-hydroxy-9,10-dioxo-9,10-dihydroanthracene-2-sulfonate (5). ${ }^{6}$ Degradations of RBBR (1) by an immobilized laccase of Trametes pubescens and by Aspergillus flavus also produced 5., Since RBBR (1) degradation by Tinctoporellus sp. CBMAI 1061 is likely promoted by a laccase, ${ }^{9}$ enzymes that promote free radical oxidations, ${ }^{10}$ the introduction of the hydroxyl group in RBBR is likely to proceed via a free radical mechanism. Bond cleavage between the anthraquinone and the substituted aniline may be catalyzed by a cytochrome $\mathrm{P}_{450}$ enzyme, a well-known aniline dealkylating enzymatic reaction. ${ }^{\mathbf{1 1 - 1 3}}$

To the best of our knowledge this is the first investigation in which products of RBBR (1) fungal degradation were isolated and identified by rigorous NMR and MS analysis. Moreover, the anthraquinones 2, 3 and 4 are unprecedented. Since anthraquinones exert an array of potent biological activities, ${ }^{19}$ the isolation of 2, 3, 4 and 5 are of interest but the low yields we obtained precluded the evaluation of these compounds in biological screens. While the isolation of the halogenated products 

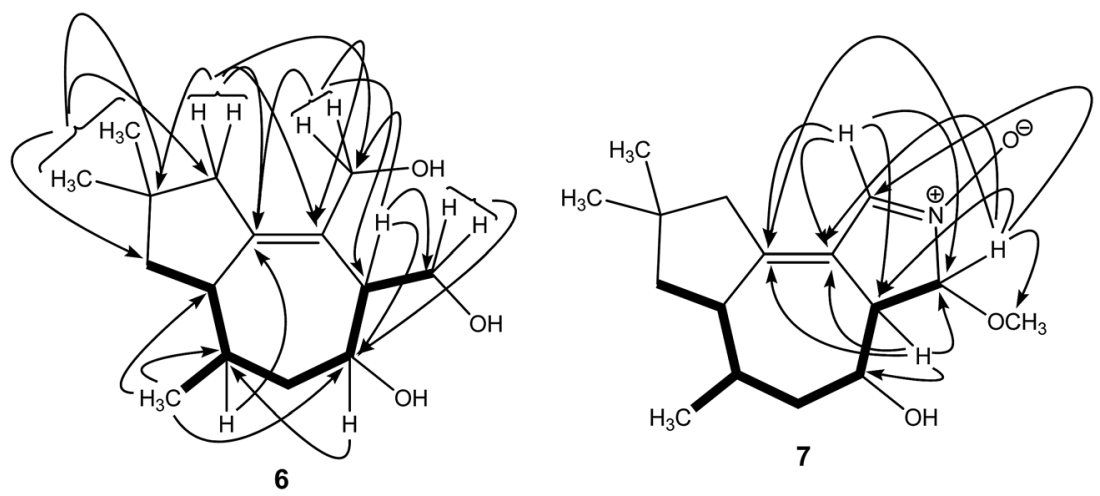

Fig. 1 Key COSY (bold bonds) and HMBC correlations (arrows) observed for compounds 6 and 7.

3 and $\mathbf{4}$ was completely unexpected since no bromine or chlorine salts were added to the medium, the composition of malt broth may well include chlorine and bromine salts that may represent halogen sources for the transformation of RBBR (1) into 3 and 4.

While investigating the formation of RBBR (1) degradation products in the growth medium of Tinctoporellus sp. CBMAI 1061, analysis by HPLC-UV-MS enabled us to detect the presence of additional culture products with UV absorptions in the region $\lambda_{\max } 290-300 \mathrm{~nm}$, as well as $[\mathrm{M}+\mathrm{H} / \mathrm{Na}]^{+}$ions with $\mathrm{m} / z$ 266-303. Purification of these compounds by HPLC led to the isolation of the tremulene terpenes 6-8, of which 7 and 8 are new 2-hydroxy- or 2-methoxy-3,4-dihydro- $2 \mathrm{H}$-pyrrole $\mathrm{N}$-oxide terpene derivatives. The nitrogen-bearing $2-H$-pyrrole pyrrole $\mathrm{N}$-oxide moieties in 7 and $\mathbf{8}$ have apparently not been previously reported in terpenoid natural products, although they are well known synthetically.

Tremulenetriol (6) gave a $[\mathrm{M}+\mathrm{Na}]^{+}$ion in the HRESIMS at $\mathrm{m} / \mathrm{z}$ 277.1782 appropriate for a molecular formula of $\mathrm{C}_{15} \mathrm{H}_{26} \mathrm{O}_{3}$. Olefinic resonances at at $\delta 142.1$ and 130.8 in the ${ }^{13} \mathrm{C} \mathrm{NMR}$ spectrum accounted for one of the three sites of unsaturation required by the molecular formula, requiring that 6 had to contain two rings. In the ${ }^{1} \mathrm{H}$ NMR spectrum, two aliphatic methyl singlets $(\delta$ 1.03/0.79; Me-14, Me-15) and one methyl doublet $(\delta$ $0.86, J=6.7 \mathrm{~Hz}$; Me-13) were observed. Analysis of the gCOSY and gHSQC spectra of 6 unambiguously identified two isolated methylenes, one oxygenated $\left(\delta_{\mathrm{H}} 3.89\right.$ and $\left.3.74 / \delta_{\mathrm{C}} 64.0, \mathrm{CH}_{2}-11\right)$ and one as an alkyl substituent $\left(\delta_{\mathrm{H}} 2.17\right.$ and $1.82 / \delta_{\mathrm{C}} 47.0, \mathrm{CH}_{2}-$ $10)$, as well as a linear spin system which is shown in bold in Fig. 1. The structure of the linear spin system extending from C12 through to $\mathrm{C}-8$, with a methyl branch (Me-13) at C-6, was confirmed by analysis of the HMBC spectrum (Fig. 1). The three fragments, the two isolated methylenes and the linear C-12 to C-8 spin system, along with a gem-dimethyl group, could be connected via a series of gHMBC correlations [Me-14/15 $(\delta 0.80 / 1.03)$ to C-8 ( $\delta 43.3)$, C-9 $(\delta 37.2), \mathrm{C}-10(\delta 47.0)$; $\mathrm{H}-10(\delta 2.17 / 1.82)$ to $\mathrm{C}-1$ $(\delta$ 142.1) and C-2 ( $\delta 130.8) ; \mathrm{H}-11(\delta 3.89 / 3.74)$ to $\mathrm{C}-1, \mathrm{C}-2$ and $\mathrm{C}-3(\delta$ 53.2); H-3 ( $\delta 2.50)$ to $\mathrm{C}-1$ and $\mathrm{C}-2 ; \mathrm{H}-12(\delta 3.53)$ to $\mathrm{C}-2]$ summarized with arrows in Fig. 1, establishing the linear carbon backbone of the terpene chain from C-1 to C-10 and the locations of the tetrasubstituted alkene, of the branched methyl (Me-13), of the branched oxygenated methylenes (C-11 and C-12) and of the gem-dimethyl (Me-14/15). gHMBC correlations observed between C-1 $(\delta$ 142.1) and both H-6 $(\delta$ 1.70) and H-8 ( $\delta 1.39$ and 1.35), between $\mathrm{H}-7$ ( $\delta$ 2.94) and C-2 ( $\delta$ 130.8), and between $\mathrm{H}-10(\delta 2.17)$ and $\mathrm{C}-7$ ( $\delta$ 43.3) identified a bond between $\mathrm{C}-1$ and $\mathrm{C}-7$, which created the two required rings from the linear terpene backbone. To satisfy the molecular formula, the three oxygenated carbons C-4, C-11 and C-12 had to bear secondary and two primary hydroxy substituents, respectively. The relative configuration of 6 was established by the series of tROESY correlations illustrated in Fig. 2. tROESY correlations observed between $\mathrm{H}-7$ ( $\delta$ 2.94) and $\mathrm{H}$ $4(\delta$ 3.94), H-5a $(\delta$ 1.78), H-6 ( $\delta$ 1.70), H-12 $(\delta$ 3.53) and Me-14 $(\delta$ $0.79)$, as well as between $\mathrm{H}-4(\delta 3.95)$ and both $\mathrm{H}-6(\delta 1.70)$ and $\mathrm{H}-$
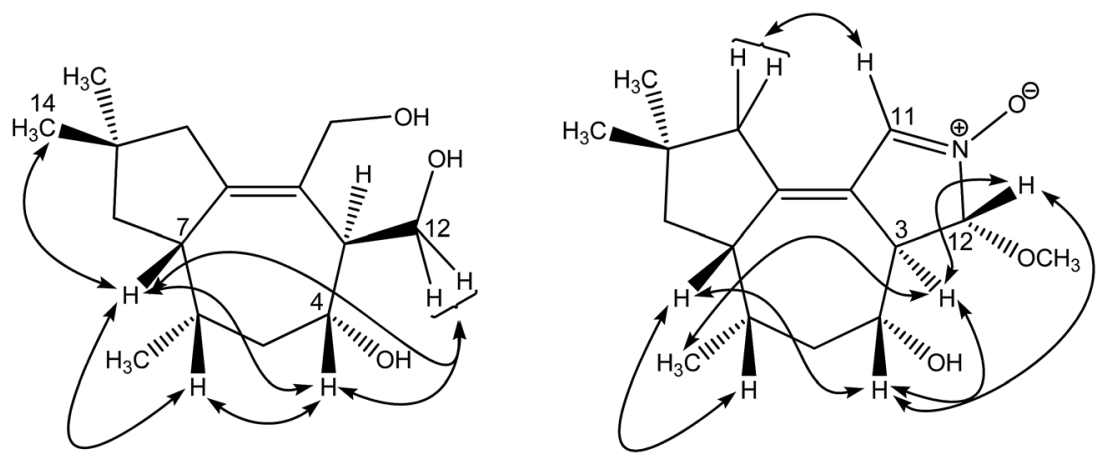

Fig. 2 tROESY correlations observed for compounds 6 and 7. Dashed curves indicate weak correlations. 
Table $1{ }^{13} \mathrm{C}$ and ${ }^{1} \mathrm{H}$ NMR data of anthraquinones $2,3,4$ and 5 in DMSO- $d_{6}$ [ $\delta$, multiplicity $(J$ in $\left.\mathrm{Hz})\right]$

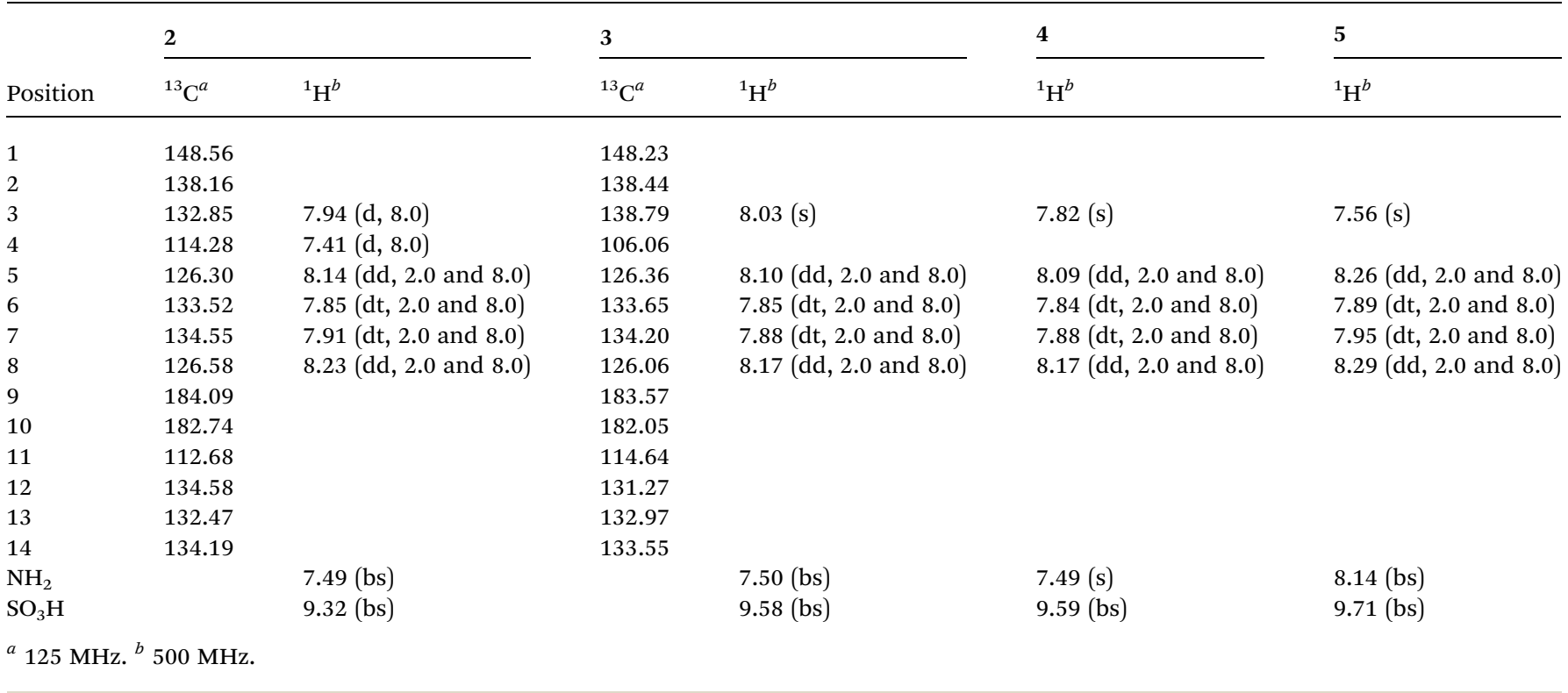

12 ( $\delta$ 3.53) meant that $\mathrm{C}-12, \mathrm{H}-4, \mathrm{H}-6$ and $\mathrm{H}-7$ were in a cis relationship, all on the same face of the seven membered ring in 6 (Fig. 2). Therefore, the relative configuration of $\mathbf{6}$, named tremulenetriol, was defined as $3 S^{*}, 4 R^{*}, 6 S^{*}, 7 S^{*}$. The ${ }^{1} \mathrm{H}$ and ${ }^{13} \mathrm{C}$ assignments of $\mathbf{6}$ were in good agreement with those reported for tremulenediol (9), previously isolated from the growth medium of the wood rotting fungus Phellinus tremulae..$^{20}$

Tremulenimine $N$-oxide A (7) gave a $[\mathrm{M}+\mathrm{H}]^{+}$ion in the HRESIMS at $m / z \quad 280.1916$ appropriate for the molecular formula of $\mathrm{C}_{16} \mathrm{H}_{25} \mathrm{NO}_{3}$, that differs from the formula of 6 by the addition of carbon and nitrogen atoms and the loss of a hydrogen atom and requires two additional sites of unsaturation. The NMR spectra obtained for 7 were similar to the spectra of 6 except that the resonances assigned to the methylenes of the primary alcohols at C-11 and C-12 were missing. These had been replaced by a proton singlet resonating at $\delta 7.31(\mathrm{H}-11)$, correlated in the gHSQC to a downfield olefinic carbon resonance at $\delta 132.7$ (C-11), and a proton resonance at $\delta 4.90(\mathrm{~d}, J=6.3 \mathrm{~Hz} ; \mathrm{H}-12)$ correlated in the gHSQC to a carbon resonance at $\delta 101.9(\mathrm{C}-12)$. The chemical shifts of the carbon resonance at $\delta 101.9$ and its attached proton $(\delta$ 4.90) were appropriate for a hemiacetal or hemiaminal functionality. Additionally, an oxy-methyl singlet at $\delta 3.65$ was correlated to a carbon at $\delta 59.3$ in the gHSQC spectrum. The doublet at $\delta 4.90$

Table $2{ }^{13} \mathrm{C}$ and ${ }^{1} \mathrm{H}$ NMR data of compounds 6,7 and 8 [ $\delta$, multiplicity $(\mathrm{J}$ in $\left.\mathrm{Hz})\right]$

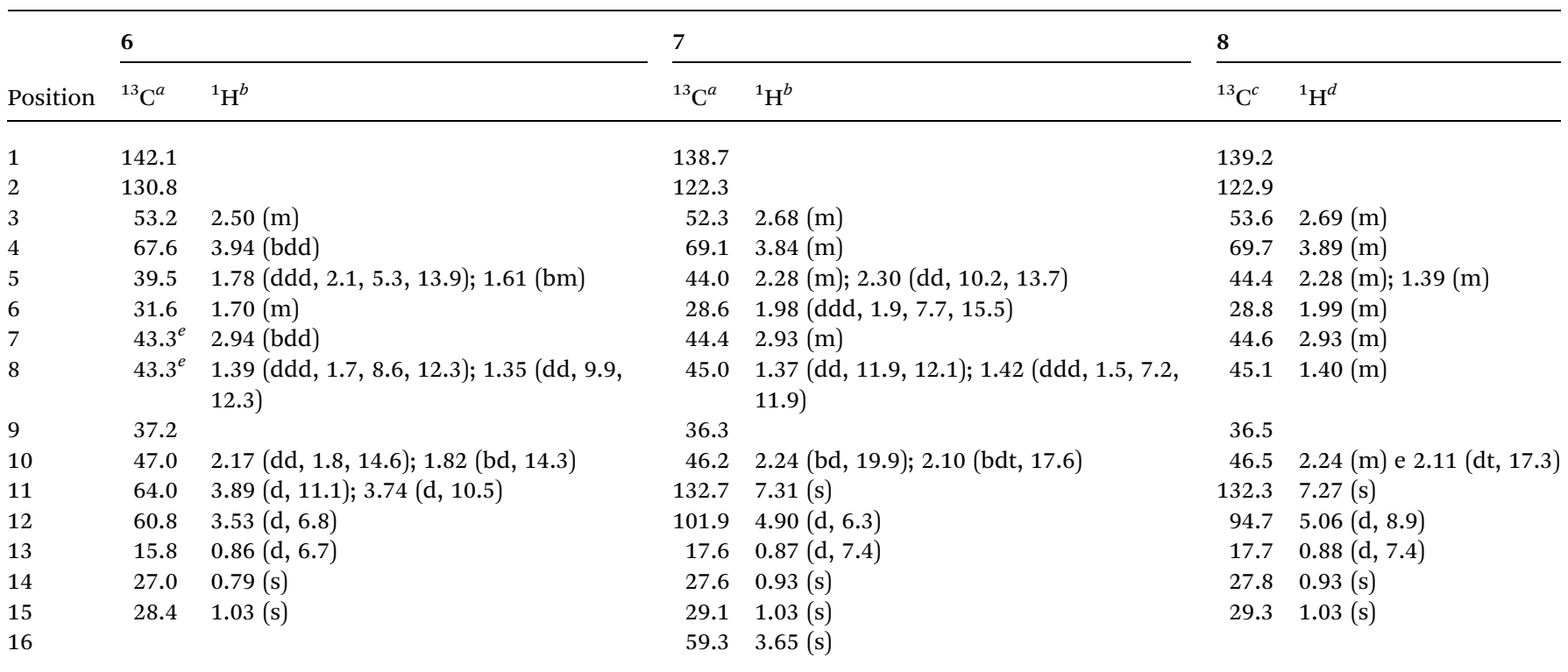

${ }^{a} 150 \mathrm{MHz} .{ }^{b} 600 \mathrm{MHz} .{ }^{c} 100 \mathrm{MHz} .{ }^{d} 400 \mathrm{MHz} .{ }^{e}$ Overlapping signals. 
$(\mathrm{H}-12)$ was coupled to the resonance assigned to $\mathrm{H}-3$ at $\delta 2.68$ in the gCOSY spectrum of 7, while the methoxy resonance at $\delta 3.65$ (Me-16) correlated to the carbon at $\delta 101.9$, assigned to the C-12 methine, in the gHMBC spectrum. The methine proton resonance at $\delta 4.90$ (H-12) showed HMBC correlations to both C-2 $(\delta$ 122.3) and $\mathrm{C}-11(\delta$ 132.7), while $\mathrm{H}-11(\delta$ 7.31) correlated to C-1 $(\delta$ 138.7), C-2 ( $\delta$ 122.3), C-3 ( $\delta$ 52.3) and C-12 ( $\delta$ 101.9). In the gCOSY spectrum, H-11 $(\delta$ 7.31) and H-12 ( $\delta 4.90)$ showed a weak long-range $\mathrm{W}$ coupling.

The above NMR evidence was consistent with a structure for 7 containing a nitrone group linking C-11 to C-12 to give a 3,4dihydro-2H-pyrrole 1-oxide substructure having a methoxy substituent at $\mathrm{C}-12$. This proposed structure for 7 contains the two additional sites of unsaturation and the additional atoms required by the molecular formula. As with tremulenetriol (6), the relative configuration of 7 was established by the series of tROESY correlations illustrated in Fig. 2, which showed that at the common stereogenic centers 6 and 7 had identical absolute configurations. The tROESY correlations observed for 7 included $\mathrm{H}-7$ ( $\delta$ 2.93) to $\mathrm{H}-6(\delta$ 1.98) and $\mathrm{H}-4$ ( $\delta 3.84)$, and both $\mathrm{H}-3(\delta 2.68)$ and $\mathrm{H}-4(\delta 3.84)$ to $\mathrm{H}-12(\delta 4.90)$. A tROESY correlation between $\mathrm{H}-3(\delta$ 2.68) and Me-13 ( $\delta$ 0.87) confirmed that $\mathrm{H}-3$ and $\mathrm{C}-13$ were cis, as in 6 . On the basis of the observed tROESY correlations, the relative configuration of tremulenimine 1-oxide A (7) was assigned as $3 R^{*}, 4 R^{*}, 6 S^{*}, 7 S^{*}$, $12 R^{*}$. The 3,4-dihydro- $2 H$-pyrrole 1-oxide moiety in tremulenimine 1-oxide A (7) has to the best of our knowledge not been previously reported in a natural product.

Tremulenimine $N$-oxide B (8) gave a $[\mathrm{M}+\mathrm{H}]^{+}$ion in the HRESIMS at $m / z 266.17623$ appropriate for the molecular formula of $\mathrm{C}_{15} \mathrm{H}_{23} \mathrm{NO}_{3}$, that differs from the formula of 7 by the loss of a methylene. The NMR spectra obtained for 8 were remarkably similar to the spectra of 7 except that the resonances assigned to the methoxy moiety in 7 , at $\delta_{\mathrm{H}} 3.66(\mathrm{~s}) / \delta_{\mathrm{C}} 59.4$, were no longer observed. Replacement of the methoxy with a hydroxyl group would account for these NMR differences. Analysis of the 2D NMR data of 8 confirmed this hypothesis, with the C-12 resonance in $\mathbf{8}$, at $\delta 94.7$, slightly shielded relative to that seen in 7 , at $\delta$ 102.0. Although degradation of 8 prevented the collection of tROESY and optical rotation data, the close similarity of the ${ }^{1} \mathrm{H}$ and ${ }^{13} \mathrm{C}$ NMR spectra of $\mathbf{8}$ and 7 strongly suggests the same relative configuration for the two compounds.

The isolation of nitrones ( $N$-oxides) 7 and 8 is intriguing. In the absence of RBBR the tremulene terpenes could not be detected by HPLC-UV-MS analysis from cultures of Tinctoporellus sp. CBMAI 1061. Also, the production of the these terpenes was not observed with the addition of hydroxylamine to the growth medium. Therefore, it would appear that the addition of RBBR to Tinctoporellus sp. CBMAI 1061 cultures is a requirement for the production of the terpenes. However, the reasons for why RBBR is needed to stimulate the biosynthesis of the terpenes remains uncertain.

Tremulanes, for example tremulenediol A (9), were first isolated from cultures of the aspen (Populus tremuloides) rotting fungus Phellinus tremulae. ${ }^{\mathbf{2 0}}$ Although these sesquiterpenes first appeared as non-regular terpenes, ${ }^{20}$ subsequent biosynthetic investigations provided evidence that the tremulane skeleton originates from farnesyl pyrophosphate, via humulene formation and a methyl group migration. ${ }^{21}$ Recently, a series of tremulene and tremulane terpenes have been isolated from various fungal strains. ${ }^{22-27} 5 \alpha, 12$-Dihydroxy-1-tremulen-11-yl $2(S)$-pyroglutamate was isolated from the basidiomycete Conocybe siliginea as the first tremulene derivative bearing a nitrogen-containing 2(S)-pyroglutamate moiety. ${ }^{26}$ Tremulene terpenes have shown moderate cytotoxic activity ${ }^{22}$ and vascularrelaxing activities against phenylephrine-induced vasoconstriction. ${ }^{25}$ Curiously, this class of rearranged sesquiterpenes is restricted to fungi.

\section{Conclusions}

We have investigated the degradation of the dye RBBR (1) by the marine-derived fungus Tinctoporellus sp. CBMAI 1061, which lead to the formation of the new anthraquinones 2-5. This was the first investigation of RBBR (1) degradation by a fungal strain in which the degradation products were unambiguously characterized by NMR and MS analyses. Moreover, the tremulene terpenes 6-8 have been isolated from the RBBR degradation medium as products of Tinctoporellus sp. CBMAI 1061 metabolism. The tremulenes 7 and 8 are the first secondary metabolites with 3,4-dihydro- $2 H$-pyrrole 1 oxide substructures. Further investigations of the medium and growth requirements for improved production of metabolites by the fungus Tinctoporellus sp. CBMAI 1061 in the presence of RBBR (1) are underway in order to produce the additional amounts of compounds 2-8 required for evaluation in biological assays.

\section{Experimental section}

\section{General experimental procedures}

Optical rotations were measured using a Jasco P-2000 polarimeter in $\mathrm{MeOH}$, at $25^{\circ} \mathrm{C}$. UV analysis was performed using a Jasco V-630 spectrophotometer. High resolution FTESIMS were recorded with a LTQ-Orbitrap Velos (Thermo Fisher Scientific) in direct infusion ESI ionization mode, with a voltage discharge at $3700 \mathrm{~V}$ and capilar temperature of $350{ }^{\circ} \mathrm{C}$. Low and high resolution ESI-QITMS were recorded on a Bruker-Hewlett Packard 1100 Esquire-LC system mass spectrometer. NMR spectra were recorded on an Agilent Technologies 500/54 Premium Shielded spectrometers operating at $499.85 \mathrm{MHz}\left({ }^{1} \mathrm{H}\right)$ or $125.70 \mathrm{MHz}\left({ }^{13} \mathrm{C}\right)$, using tetramethylsilane (TMS) as an internal standard, or on a Bruker AV600 spectrometer with a $5 \mathrm{~mm}$ CPTCI cryoprobe, for which the ${ }^{1} \mathrm{H}$ chemical shifts are referenced to the residual DMSO- $d_{6}$ signal $(\delta 2.49 \mathrm{ppm})$ and ${ }^{13} \mathrm{C}$ chemical shifts are referenced to the DMSO$d_{6}$ solvent peak ( $\delta 39.5 \mathrm{ppm}$ ). HPLC-UV-MS analyses were performed using a Waters Alliance 2695 chromatographic controller coupled in series to a Waters 2996 photodiode array detector operating in the range between 200 and $800 \mathrm{~nm}$ and a Waters Micromass ZQ 2000 mass spectrometer detector operating in the range between 200 and $1000 \mathrm{Da}$, using ESI ionization, temperature of the ionization source at $100{ }^{\circ} \mathrm{C}$, desolvation temperature at $300{ }^{\circ} \mathrm{C}$ and cone gas flow at $50 \mathrm{~L} \mathrm{~h}^{-1}$. The HPLC-UV-MS analyses were performed using a GL-Sciences Inc. Inertsil phenyl $(4.6 \mathrm{~mm}$ $\times 250 \mathrm{~mm}, 5 \mu \mathrm{m}$ ) column. The elution gradient was performed using a $1: 1$ mixture of $\mathrm{MeOH}+0.1 \% \mathrm{HCO}_{2} \mathrm{H}$ and $\mathrm{MeCN}+0.1 \%$ 
$\mathrm{HCO}_{2} \mathrm{H}$ as the organic solvent and a $30 \mathrm{mM}$ acetic acid/ ammonium acetate buffer $(\mathrm{pH} 4.5)$ as the aqueous phase. Elution was performed starting with $40 \%$ of organic phase until $80 \%$ of organic phase during $20 \mathrm{~min}$, remaining at $80 \%$ organic phase during $10 \mathrm{~min}$, then decreasing to the initial conditions

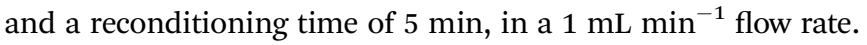

\section{Fungal strain}

The strain Tinctoporellus sp. CBMAI 1061 was isolated from a specimen of the sponge Dragmacidon reticulatum and identified as previously described. ${ }^{\mathbf{9} 28}$ The strain has been maintained in the Brazilian Collection of Industrial and Environmental Microorganisms (CBMAI) at Universidade Estadual de Campinas (CPQBA/UNICAMP).

\section{Fungal growth and RBBR degradation}

Pellets of $0.5 \mathrm{~cm}$ diameter were obtained from $2 \%$ malt extract solid medium on which Tinctoporellus sp. CBMAI 1061 was grown. Twelve pellets were used to inoculate $500 \mathrm{~mL}$ Schott flasks containing $200 \mathrm{~mL}$ of $2 \%$ malt broth, that were maintained at $28{ }^{\circ} \mathrm{C}$ and $160 \mathrm{rpm}$ for $72 \mathrm{~h}$. Then, a $20 \mathrm{~mL}$ aliquot of a 500 ppm solution of RBBR (1) was filtered through a $0.22 \mu \mathrm{m}$ membrane (Millipore) and added to each flask, which were then re-incubated at $28{ }^{\circ} \mathrm{C}$ and $160 \mathrm{rpm}$. During the following 17 days, medium aliquots of $1 \mathrm{~mL}$ were collected each day. The aliquots were filtered and subjected to UV analysis at $\lambda_{\max }$ $580 \mathrm{~nm}$, until the disappearance of RBBR UV absorption bands was complete. Degradation was found to be complete after 12 days. Under the same conditions a larger scale RBBR (1) degradation by Tinctoporellus sp. CBMAI 1061 was performed with 30 Schott flasks for 12 days.

\section{Medium extraction and metabolites isolation}

At the end of the larger scale RBBR (1) degradation experiment, the medium was filtered through a pad of celite. The filtered medium was extracted with $10 \% \mathrm{v} / \mathrm{v}$ of a $1: 1: 1$ mixture of the resins Amberlite XAD-2, XAD- 4 and XAD-7 for $24 \mathrm{~h}$ with gentle shaking. The resin mixture was separated by filtration and the aqueous fraction was discarded. The resin mixture was extracted with $1: 1 \mathrm{MeOH} /$ acetone for 2 hours and then filtered. The organic extract was evaporated and dried in vacuo, to give $1.2 \mathrm{~g}$ of a crude extract. This extract was fractionated in $400 \mathrm{mg}$ aliquots on a Sephadex LH-20 $(170 \times 2 \mathrm{~cm}$ column $)$ column with $\mathrm{MeOH}$ as eluent. The resulting fractions were analyzed by TLC, using $8: 2 \mathrm{CH}_{2} \mathrm{Cl}_{2} / \mathrm{MeOH}$ as eluent, and observed under UV light at $\lambda_{\max } 254 \mathrm{~nm}$. The six fractions obtained were analyzed by HPLCUV-MS. A later eluting fraction ( $21 \mathrm{mg}$ ) was chromatographed on a $\mathrm{C}_{18}$ reversed-phase column ( $2 \mathrm{~g}$ ) with gradient elution from $\mathrm{H}_{2} \mathrm{O}$ to $\mathrm{MeOH}$ to give 12 fractions which were individually analyzed by HPLC-UV-MS. The $10 \% \mathrm{MeOH}$ and $30 \% \mathrm{MeOH}$ fractions were combined $(7.7 \mathrm{mg})$ and fractionated by HPLC using an Inertsil phenyl $(4.6 \mathrm{~mm} \times 250 \mathrm{~mm}, 5 \mu \mathrm{m})$ column with $24: 76 \mathrm{MeCN} / 30 \mathrm{mM} \mathrm{AcOH} / \mathrm{AcONH}_{4}$ buffer (pH 4.5) as eluent to yield anthraquinones 2 (3.0 mg), $3(1.9 \mathrm{mg}), \mathbf{4}(1.2 \mathrm{mg})$ and 5 (1.0 $\mathrm{mg}$ ). Anthraquinones 3 and 5 were purified by HPLC using a $\mathrm{C}_{18}$ reversed-phase InertSustain column $(25 \times 1 \mathrm{~cm}, 5 \mu \mathrm{m})$, with 70 : $30\left(0.05 \%\right.$ TFA in $\left.\mathrm{H}_{2} \mathrm{O}\right) / \mathrm{MeCN}$ as eluent at $2 \mathrm{~mL} \mathrm{~min}^{-1}$.

A second fraction ( $854 \mathrm{mg}$ ) obtained from the Sephadex LH-20 chromatography was also fractionated by reversed-phase $\mathrm{C}_{18}(10 \mathrm{~g})$ using a gradient of $\mathrm{H}_{2} \mathrm{O}$ to $\mathrm{MeOH}$ to give six fractions. A second purification on $\mathrm{a}_{18}$ column $(5 \mathrm{~g})$ of the $3: 2$ and $4: 1$ $\mathrm{MeOH} / \mathrm{H}_{2} \mathrm{O}$ fractions with a gradient of $\mathrm{MeOH}$ in $\mathrm{H}_{2} \mathrm{O}$ resulted in nine and six fractions, respectively. The $3: 2(75 \mathrm{mg})$ and $1: 1$ (62 mg) $\mathrm{MeOH} / \mathrm{H}_{2} \mathrm{O}$ fractions were further purified by HPLC using an Inertsil phenyl column $(4.6 \mathrm{~mm} \times 250 \mathrm{~mm}, 5 \mu \mathrm{m})$ with either $1: 1: 8 \mathrm{MeCN} / \mathrm{MeOH} / \mathrm{H}_{2} \mathrm{O}$ or $1: 4 \mathrm{MeCN} / \mathrm{H}_{2} \mathrm{O}$ as eluent to give compounds 6 (17 mg), 7 (5 mg) and 8 (3.3 mg). During solvent solubility testing for NMR analyses, partial degradation of compounds 6-8 occurred which required re-purification under the same HPLC conditions to give samples of $\mathbf{6}$ (3.0 mg), 7 (3.4 mg) and $8(1.0 \mathrm{mg})$ in $80-90 \%$ purity. A final $\mathrm{C}_{18}$ reversed-phase HPLC purification using an InertSustain $5 \mu \mathrm{m}$, $25 \times 1.0 \mathrm{~cm}$ column, with for $613: 7$ and for $77: 3 \mathrm{H}_{2} \mathrm{O} / \mathrm{MeCN}$ as eluent gave pure samples of $6(1.6 \mathrm{mg})$ and $7(0.5 \mathrm{mg})$.

1-Amino-9,10-dioxo-9,10-dihydroanthracene-2-sulfonic acid 2. Glassy solid; UV (MeOH) $\lambda_{\max }(\log \varepsilon) 248$ (2.36), 277 (1.95), and 478 (1.69); ${ }^{1} \mathrm{H}$ NMR and ${ }^{13} \mathrm{C}$ NMR (DMSO- $d_{6}$ ) see Table 1; HRFTESIMS (neg.) $m / z 302.0117$ (calcd for $\mathrm{C}_{14} \mathrm{H}_{8} \mathrm{NO}_{5} \mathrm{~S}[\mathrm{M}-\mathrm{H}]^{-}$, 302.0123).

1-Amino-4-bromo-9,10-dioxo-9,10-dihydroanthracene-2-sulfonic acid 3. Glassy solid; UV (MeOH) $\lambda_{\max }(\log \varepsilon) 246$ (2.38), 311 (1.67), and 485 (1.75); ${ }^{1} \mathrm{H}$ NMR and ${ }^{13} \mathrm{C}$ NMR (DMSO- $d_{6}$ ) see Table 1; HRFTESIMS (neg.) $m / z \quad 379.9230$ (calcd for $\mathrm{C}_{14} \mathrm{H}_{7} \mathrm{NO}_{5} \mathrm{~S}^{79} \mathrm{Br}$ $[\mathrm{M}-\mathrm{H}]^{-}$, 379.9228).

1-Amino-4-chloro-9,10-dioxo-9,10-dihydroanthracene-2-sulfonic acid 4. Glassy solid; UV (MeOH) $\lambda_{\max }(\log \varepsilon) 246$ (2.07), 310 (1.37), and 488 (1.47); ${ }^{1} \mathrm{H}$ NMR and ${ }^{13} \mathrm{C}$ NMR (DMSO- $d_{6}$ ) see Table 1 ; HRFTESIMS (neg.) $\mathrm{m} / \mathrm{z} 335.9733$ (calcd for $\mathrm{C}_{14} \mathrm{H}_{7} \mathrm{NO}_{5} \mathrm{~S}^{35} \mathrm{Cl}$ $\left.[\mathrm{M}-\mathrm{H}]^{-}, 335.9733\right)$.

1-Amino-4-hydroxy-9,10-dioxo-9,10-dihydroanthracene-2sulfonic acid 5. Glassy solid; UV $(\mathrm{MeOH}) \lambda_{\max }(\log \varepsilon) 251$ (2.08), 288 (1.47), and 539 (1.62); ${ }^{1} \mathrm{H}$ NMR and ${ }^{13} \mathrm{C}$ NMR (DMSO- $d_{6}$ ) see Table 1 ; HRFTESIMS (neg.) $\mathrm{m} / z 318.0073$ (calcd for $\mathrm{C}_{14} \mathrm{H}_{8} \mathrm{NO}_{6} \mathrm{~S}[\mathrm{M}-\mathrm{H}]^{-}, 318.0072$ ).

Tremulenetriol (6). Amorphous clear solid; $[\alpha]_{\mathrm{D}}=+17.4$ (c 0.00155, MeOH); ${ }^{1} \mathrm{H}$ NMR and ${ }^{13} \mathrm{C}$ NMR (DMSO- $d_{6}$ ) see Table 2; HRESIMS (pos.) $m / z 277.1782$ (calcd for $\mathrm{C}_{15} \mathrm{H}_{26} \mathrm{O}_{3} \mathrm{Na}[\mathrm{M}+\mathrm{Na}]^{+}$, 277.1780).

Tremulenimine $\mathbf{N}$-oxide A (7). Amorphous pale yellow solid; $[\alpha]_{\mathrm{D}}=+3.6(c 0.00175, \mathrm{MeOH}) ;{ }^{1} \mathrm{H}$ NMR and ${ }^{13} \mathrm{C}$ NMR (DMSO$d_{6}$ ) see Table 2; HRESIMS (pos.) $\mathrm{m} / \mathrm{z} 280.1916$ (calcd for $\left.\mathrm{C}_{16} \mathrm{H}_{26} \mathrm{NO}_{3}[\mathrm{M}+\mathrm{H}]^{+}, 280.1913\right)$.

Tremulenimine $\boldsymbol{N}$-oxide B (8). Pale yellow solid; ${ }^{1} \mathrm{H}$ NMR and ${ }^{13} \mathrm{C}$ NMR (DMSO- $d_{6}$ ) see Table 2; HRFTESIMS (pos.) $\mathrm{m} / \mathrm{z}$ 266.17623 (calcd for $\mathrm{C}_{15} \mathrm{H}_{24} \mathrm{NO}_{3}[\mathrm{M}+\mathrm{H}]^{+}, 266.17562$ ).

\section{Acknowledgements}

This work was supported in part by a grant from the BIOTA/ BIOprospecTA FAPESP program (grants 2010/50190-2 and 2013/ 50228-8) and a CNPq researcher fellowship awarded to RGSB (301289/2009-3). JPGR thanks CNPq for a MSc scholarship. 
Financial support at UBC was provided by an NSERC grant to RJA. The content is solely the responsibility of the authors and does not necessarily represent the official views of the funding agencies.

\section{References}

1 Anonymous, Paint Coat. Ind., 2012, 28, 8.

2 K. Hunger, in Industrial Dyes: Chemistry, Properties, Applications, Wiley, New York, 2007, pp. 119-130.

3 J. F. Osma, J. L. Toca-Herrera and S. Rodríguez-Couto, Bioresour. Technol., 2010, 101, 8509.

4 T.-H. Bui, M. Karkmaz, E. Puzenat, C. Guillard and J.-M. Herrmann, Res. Chem. Intermed., 2007, 33, 421.

5 M. da Silva, M. R. Z. Passarini, R. C. Bonugli and L. D. Sette, Environ. Technol., 2008, 29, 1331.

6 T. Hadibarata, A. R. M. Yusoff and R. A. Kristanti, Water, Air, Soil Pollut., 2012, 223, 933.

7 R. C. Bonugli-Santos, L. R. Durrant and L. D. Sette, Water, Air, Soil Pollut., 2012, 223, 2333.

8 B. Perlatti, M. F. D. F. da Silva, J. B. Fernandes and M. R. Forim, Bioresour. Technol., 2012, 124, 37-44.

9 R. C. Bonugli-Santos, L. R. Durrant and L. D. Sette, Fungal Biol., 2010, 114, 863.

10 C. M. Rivera-Hoyos, E. D. Morales-Alvarez, R. A. PoutouPiñales, A. M. Pedroza-Rodríguez, R. Rodríguez-Vasquez and J. M. Delgado-Boada, Fungal Biol. Rev., 2013, 27, 67.

11 J. P. Dinnocenzo, S. B. Karki and J. P. Jones, J. Am. Chem. Soc., 1993, 115, 7111.

12 S. B. Karki, J. P. Dinnocenzo, J. P. Jones and K. R. Korzekwa, J. Am. Chem. Soc., 1995, 117, 3657.
13 M. N. Bhakta and K. Wimalasena, Eur. J. Org. Chem., 2005, 4801.

14 G. Palmieri, G. Cennamo and G. Sannia, Enzyme Microb. Technol., 2005, 36, 17.

15 B. R. M. Vyas and H. P. Molitoris, Appl. Environ. Microbiol., 1995, 61, 3919.

16 G. M. B. Soares, M. Costa-Ferreira and M. T. P. de Amorim, Bioresour. Technol., 2001, 79, 171.

17 A. Kasinath, C. Novotny, K. Svobodova, K. C. Patel and V. Sasek, Enzyme Microb. Technol., 2003, 32, 167.

18 I. Eichlerova, L. Homolka and F. Nerud, Bioresour. Technol., 2006, 97, 2153.

19 M. Locatelli, Curr. Drug Targets, 2011, 12, 366.

20 W. Ayer and E. R. Cruz, J. Org. Chem., 1993, 58, 7529.

21 E. R. Cruz, Can. J. Chem., 1997, 75, 834.

22 Y. M. Ying, W. G. Shan, L. W. Zhang and Z. J. Zhan, Phytochemistry, 2013, 95, 360.

23 X. Yang, T. Feng, X. Yin, Z. Li, L. Zhang and J. Liu, Chin. J. Chem., 2012, 30, 1231.

24 W.-G. Shan, D.-E. Liang, Y.-M. Ying and Z.-J. Zhan, J. Chem. Res., 2012, 365-366.

25 X. Wu, S. Lin, C. Zhu, Z. Yue, Y. Yu, F. Zhao, B. Liu, J. Dai and J. Shi, J. Nat. Prod., 2010, 73, 1294.

26 Z.-Y. Zhou, J.-G. Tang, F. Wang, Z.-J. Dong and J.-K. Liu, J. Nat. Prod., 2008, 71, 1423.

27 D.-Z. Liu, F. Wang and J.-K. Liu, J. Nat. Prod., 2007, 70, 1503.

28 C. B. Menezes, R. C. Bonugli-Santos, P. B. Miqueletto, M. R. Z. Passarini, C. H. D. Silva, M. R. Justo, R. R. Leal, F. Fantinatti-Garboggini, V. M. Oliveira, R. G. S. Berlinck and L. D. Sette, Microbiol. Res., 2010, 165, 466. 